\title{
Histopathological alterations of the heart in fish: proposal for a standardized assessment
}

\section{Christoph Steinbach ${ }^{1, *}$, Hana Kocour Kroupová ${ }^{1}$, Thomas Wahli ${ }^{2}$, Jana Klicnarová ${ }^{3}$, Heike Schmidt-Posthaus ${ }^{2}$}

\author{
${ }^{1}$ Research Institute of Fish Culture and Hydrobiology, South Bohemian Research Centre of Aquaculture and \\ Biodiversity of Hydrocenoses, Faculty of Fisheries and Protection of Waters, University of South Bohemia in České Budějovice, \\ Zátiší 728/II, 389 25, Vodňany, Czech Republic \\ ${ }^{2}$ Centre for Fish and Wildlife Health, Department of Infectious Diseases and Pathobiology, University of Bern, \\ Länggass-Strasse 122, 3012 Bern, Switzerland \\ ${ }^{3}$ Faculty of Economics, University of South Bohemia in České Budějovice, Studentská 13, 37005 České Budějovice, \\ Czech Republic
}

\begin{abstract}
Histopathological alterations in the heart are often reported in fish as a result of exposure to a variety of chemical compounds. However, researchers presently lack a standardized method for the evaluation of histopathological alterations in the cardiovascular system of fish and the calculation of an 'organ index'. Therefore, we designed a method for a standardized assessment and evaluation of histopathological alterations in the heart of fish. As a model species, we used rainbow trout Oncorhynchus mykiss, but the protocol was also successfully applied to other fish species belonging to different taxonomic orders. To test the protocol, we re-evaluated sections of atenolol-exposed and unexposed rainbow trout obtained in a previous study. The results were in accordance with those previously published, demonstrating the applicability of the protocol. The protocol provides a universal method for the comparative evaluation of histopathological changes in the heart of fish.
\end{abstract}

KEY WORDS: Cardiovascular system · Functional unit $\cdot$ Heart index $\cdot$ Histopathology $\cdot$ Ventricle Valves $\cdot$ Bulbus arteriosus

Resale or republication not permitted without written consent of the publishe

\section{INTRODUCTION}

Histopathological alterations, defined as structural and functional changes in cells, tissues and organs, have been used for diagnosis of fish diseases and as biomarkers of e.g. stress and exposure to pollution and/or toxins (Haschek et al. 2010, Feist \& Segner 2013, Raskovic et al. 2013). For instance, histopathological alterations of fish gonads are used as criteria in the regulatory risk assessment of chemicals (Feist \& Segner 2013).

In assessments, histopathological alterations are presented either as simple qualitative descriptions or, at most, as semi-quantitative assessments/values. However, histopathological alterations are only uni- versally comparable if an established standardized protocol is used. Bernet et al. (1999) developed a protocol for the standardized assessment of histopathological changes in the liver, gill, kidney and skin of fish which employs the 'organ index'. This protocol provides a system to compare in an unbiased and objective way the same tissue from different individuals subjected to different treatments. Bernet et al. (1999) selected gills and skin for evaluation because they come into direct contact with pollutants, and liver and kidney due to their function in metabolism and excretion of pollutants. However, structural changes in other organs are widely used to judge effects in toxicological studies as well (Schmidt et al. 1999, Haschek et al. 2010, Marchand et al. 2012, 
Feist \& Segner 2013, Raskovic et al. 2013, Steinbach et al. 2014). In these other organs, statistical evaluations of histological changes are only possible if a standardized scheme is available.

The heart is one such tissue of interest. For example, Steinbach et al. (2014) described histopathological alterations in the heart of rainbow trout Oncorhynchus mykiss that were sub-chronically exposed to atenolol. Another study by Marchand et al. (2012) described pathologic effects of polluted river water in various tissues including the heart of North African catfish Clarias gariepinus and Mozambique tilapia Oreochromis mossambicus. With a standardized protocol for the assessment of histological alterations, statistical evaluation would be possible and studies using this scheme could complement each other, e.g. to give insights in the cardio-toxicity of selected pollutants.

Therefore, the aim of the present study was to develop and test a unified protocol for the assessment and evaluation of histopathological alterations in the heart of fish, including ventricle, atrium, valves, bulbus arteriosus, coronary blood vessels and intramyocardial capillaries. To test this protocol, samples of the heart of unexposed rainbow trout and those exposed to the beta-blocker atenolol (Steinbach et al. 2014) were re-evaluated and assessed according to the protocol. In addition, heart tissues of fish belonging to different families (Salmonidae, Cyprinidae, Acipenseridae and Percidae) were used to test the adaptability of this protocol to different fish species.

\section{MATERIALS AND METHODS}

\section{Development of the histological scheme}

The definition of the functional units of the heart and the cell types of the heart for the protocol were based on the histological atlases of Takashima \& Hibiya (1995) and Genten et al. (2009). The statistical principles are based on the protocol of Bernet et al. (1999). The assessment parameters are given in Table 1.

\section{Application of the histological scheme}

The developed protocol, as given in Table 1, was applied to heart sections of rainbow trout originating from a previous study (Steinbach et al. 2014). Briefly, fish had been exposed to atenolol at a concentration of $1000 \mathrm{Mg}^{-1}$ for $42 \mathrm{~d}$. From these fish and an un- treated control group, hearts had been removed and processed for histology. The experimental conditions are described in detail by Steinbach et al. (2014). As a basis for the determination of specific changes, a non-blind evaluation of the slides was conducted by 2 observers for 8 slides for each treatment group. After the identification of the pathology patterns, their analysis was repeated in a blind manner. After this assessment, a third observer was included for agreement. The functional unit index (Eq. 1 below) and the heart index (Eq. 2 below) for the different experimental groups (exposed and unexposed) were then calculated.

In addition, the developed protocol was applied to slides obtained from routine diagnostic work provided by the Centre for Fish and Wildlife Health (CFWH, Bern, Switzerland). The sections originated from 5 species belonging to 3 different families as follows: Cyprinidae, zebrafish Danio rerio and koi carp Cyprinus carpio; Acipenseridae, Russian sturgeon Acipenser gueldenstaedtii; and Percidae, European perch Perca fluviatilis. From each of the different species, 1 slide was evaluated according to the scheme described. For all tested fish, only sagittal sections of the heart were used.

\section{Statistical analysis}

The statistical software STATISTICA (version 12, StatSoft) was used to compare the differences between the tested groups, including the control group and differences between the 2 observers. To analyse differences within the organ indices of the exposed fish and the control fish, we used a non-parametric Kolmogorov-Smirnov (K-S) test, as we could not assume that the indices follow a normal distribution. To check the inter-observer reliability, we used Spearman's correlation. Results were considered significant at $\mathrm{p}<0.05$. All data, the heart indices and the indices of the functional units, are presented as median and upper and lower quartiles.

\section{RESULTS}

\section{Development of the histological scheme for assessment of pathological alterations in the heart}

The pathological alterations were classified into 5 reaction patterns (circulatory disturbance, regressive and progressive changes, inflammation and tumour). For each alteration, an importance factor was as- 
Table 1. Protocol for the assessment of histopathological alterations in the heart of fish. The importance factor (I) ranges from 1 to 3 (1: minimal impact; 2: moderate pathological importance; 3: severe pathological importance)

\begin{tabular}{|c|c|c|c|c|c|}
\hline $\begin{array}{l}\text { Tissue and cell type } \\
\text { Reaction pattern }\end{array}$ & Alteration & I & $\begin{array}{l}\text { Tissue and cell type } \\
\text { Reaction pattern }\end{array}$ & Alteration & I \\
\hline \multicolumn{3}{|l|}{ Coronary vessels } & \multirow[t]{7}{*}{ Regressive changes } & Architectural and structural & \\
\hline Endothelial cells & & & & alterations & 1 \\
\hline Circulatory changes & Hyperaemia & 1 & & Plasma alterations & 1 \\
\hline & Aneurysm & 1 & & Nuclear alterations & 2 \\
\hline & Thrombus & 2 & & Atrophy & 2 \\
\hline & Intercellular oedema & 1 & & Necrosis & 3 \\
\hline \multirow[t]{7}{*}{ Regressive changes } & $\begin{array}{l}\text { Architectural and structural } \\
\text { alterations }\end{array}$ & 1 & & $\begin{array}{l}\text { Rupture of the endothelial } \\
\text { cells }\end{array}$ & 1 \\
\hline & Plasma alterations & 1 & \multirow[t]{2}{*}{ Progressive changes } & Hypertrophy & 1 \\
\hline & Nuclear alterations & 1 & & Hyperplasia & 2 \\
\hline & Atrophy & 2 & \multirow[t]{2}{*}{ Tumour } & Benign tumour & 2 \\
\hline & Necrosis & 3 & & Malignant tumour & 3 \\
\hline & \multirow{2}{*}{$\begin{array}{l}\text { Rupture of the endothelial } \\
\text { cells }\end{array}$} & & \multicolumn{2}{|l|}{ Basement membrane } & \\
\hline & & 1 & Circulatory changes & Intercellular oedema & 1 \\
\hline \multirow[t]{2}{*}{ Progressive changes } & Hypertrophy & 1 & \multirow[t]{6}{*}{ Regressive changes } & Architectural and structural & \\
\hline & Hyperplasia & 2 & & alterations & 1 \\
\hline \multirow[t]{2}{*}{ Tumour } & Benign tumour & 2 & & Plasma alterations & 1 \\
\hline & Malignant tumour & 3 & & Nuclear alterations & 2 \\
\hline Basement membrane & & & & Atrophy & 2 \\
\hline \multirow[t]{2}{*}{ Circulatory changes } & Haemorrhage & 1 & & Necrosis & 3 \\
\hline & Intercellular oedema & 1 & \multirow[t]{2}{*}{ Progressive changes } & Hypertrophy & 1 \\
\hline \multirow[t]{9}{*}{ Regressive changes } & \multirow{2}{*}{$\begin{array}{l}\text { Architectural and structural } \\
\text { alterations }\end{array}$} & & & Hyperplasia & 2 \\
\hline & & 1 & \multirow[t]{2}{*}{ Tumour } & Benign tumour & 2 \\
\hline & Plasma alterations & 1 & & Malignant tumour & 3 \\
\hline & Deposits & 1 & \multicolumn{3}{|l|}{ Pericytes } \\
\hline & Nuclear alterations & 2 & Circulatory changes & Intercellular oedema & 1 \\
\hline & Atrophy & 2 & \multirow[t]{6}{*}{ Regressive changes } & Architectural and structural & \\
\hline & Necrosis & 3 & & alterations & 1 \\
\hline & Rupture of the basement & & & Plasma alterations & 1 \\
\hline & membrane & 1 & & Nuclear alterations & 2 \\
\hline Progressive changes & Hypertrophy & 1 & & Atrophy & 2 \\
\hline & Hyperplasia & 2 & & Necrosis & 3 \\
\hline Inflammation & Exudate & 1 & Progressive changes & Hypertrophy & 1 \\
\hline & Infiltration & 2 & & Hyperplasia & 2 \\
\hline & & & Tumour & Benign tumour & 2 \\
\hline Connective tissue & & & & Malignant tumour & 3 \\
\hline Circulatory changes & Haemorrhage & 1 & & & \\
\hline & Intercellular oedema & 1 & Epicardium & & \\
\hline Regressive changes & Architectural and structural & & Epithelial cells & & \\
\hline 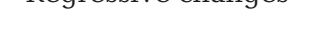 & alterations & 1 & Circulatory changes & Haemorrhage & 1 \\
\hline & Plasma alterations & 1 & & Intercellular oedema & 1 \\
\hline & Deposits & 1 & Regressive changes & Architectural and structural & \\
\hline & Nuclear alterations & 2 & & alterations & 1 \\
\hline & Atrophy & 2 & & Plasma alterations & 1 \\
\hline & Necrosis & 3 & & Deposits & 1 \\
\hline Progressive changes & Hypertrophy & 1 & & Nuclear alterations & 2 \\
\hline 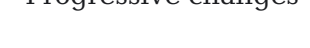 & Hyperplasia & $\begin{array}{l}1 \\
2\end{array}$ & & Atrophy & 2 \\
\hline Inflammation & Exudate & $\begin{array}{l}2 \\
1\end{array}$ & & Necrosis & 3 \\
\hline & Infiltration & 2 & Progressive changes & Hypertrophy & 1 \\
\hline Tumour & Benign tumour & 2 & & Hyperplasia & 2 \\
\hline & Malionant tumour & 3 & Inflammation & Exudate & 1 \\
\hline & Malignant tumour & 3 & & Infiltration & 2 \\
\hline Coronary capillaries & & & Tumour & Benign tumour & 2 \\
\hline Endothelial cells & & & & Malignant tumour & 3 \\
\hline Circulatory changes & Hyperaemia & 1 & Mesothelium & & C \\
\hline & Thrombus & 2 & Circulatory changes & Haemorrhage & 1 \\
\hline & Intercellular oedema & 1 & & Intercellular oedema & 1 \\
\hline
\end{tabular}


Table 1 (continued)

\begin{tabular}{|c|c|c|c|c|c|}
\hline $\begin{array}{l}\text { Tissue and cell type } \\
\text { Reaction pattern }\end{array}$ & Alteration & I & $\begin{array}{l}\text { Tissue and cell type } \\
\text { Reaction pattern }\end{array}$ & Alteration & I \\
\hline \multirow[t]{6}{*}{ Regressive changes } & \multicolumn{2}{|l|}{ Architectural and structural } & \multicolumn{3}{|l|}{$\begin{array}{l}\text { Myocardial capillary } \\
\text { Endothelial cells }\end{array}$} \\
\hline & Plasma alterations & 1 & \multirow[t]{3}{*}{ Circulatory changes } & Hyperaemia & 1 \\
\hline & Deposits & 1 & & Thrombus & 2 \\
\hline & Nuclear alterations & 2 & & Intercellular oedema & 1 \\
\hline & Atrophy & 2 & \multirow[t]{7}{*}{ Regressive changes } & Architectural and structural & \\
\hline & Necrosis & 3 & & alterations & 1 \\
\hline \multirow[t]{2}{*}{ Progressive changes } & Hypertrophy & 1 & & Plasma alterations & 1 \\
\hline & Hyperplasia & 2 & & Nuclear alterations & 2 \\
\hline \multirow[t]{2}{*}{ Inflammation } & Exudate & 1 & & Atrophy & 2 \\
\hline & Infiltration & 2 & & Necrosis & 3 \\
\hline \multirow{3}{*}{ Tumour } & Benign tumour & 2 & & Rupture of the endothelial cells & \\
\hline & Malignant tumour & 3 & \multirow[t]{2}{*}{ Progressive changes } & Hypertrophy & 1 \\
\hline & & & & Hyperplasia & \\
\hline \multirow{2}{*}{$\begin{array}{l}\text { Connective tissue } \\
\text { Circulatory changes }\end{array}$} & Haemorrhage & 1 & Tumour & Benign tumour & $\begin{array}{l}2 \\
3\end{array}$ \\
\hline & Intercellular oedema & 1 & \multirow{7}{*}{$\begin{array}{c}\text { Basement membrane } \\
\text { Circulatory changes } \\
\text { Regressive changes }\end{array}$} & Malignant tumour & 3 \\
\hline \multirow[t]{6}{*}{ Regressive changes } & $\begin{array}{l}\text { Architectural and structural } \\
\text { alterations }\end{array}$ & & & Intercellular oedema & 1 \\
\hline & Plasma alterations & $\begin{array}{l}1 \\
1\end{array}$ & & Architectural and structural & \\
\hline & Deposits & 1 & & alterations & 1 \\
\hline & Nuclear alterations & 2 & & Plasma alterations & $\begin{array}{l}1 \\
2\end{array}$ \\
\hline & Atrophy & 2 & & Atrophy & $\begin{array}{l}2 \\
2\end{array}$ \\
\hline & Necrosis & 3 & & Necrosis & 3 \\
\hline \multirow[t]{2}{*}{ Progressive changes } & Hypertrophy & 1 & \multirow[t]{2}{*}{ Progressive changes } & Hypertrophy & 1 \\
\hline & Hyperplasia & 2 & & Hyperplasia & 2 \\
\hline \multirow[t]{2}{*}{ Inflammation } & Exudate & 1 & \multirow{4}{*}{ Tumour } & Benign tumour & 2 \\
\hline & Infiltration & 2 & & Malignant tumour & 3 \\
\hline \multirow[t]{2}{*}{ Tumour } & Benign tumour & 2 & & \multirow{2}{*}{$\begin{array}{l}\text { Rupture of the basement } \\
\text { membrane }\end{array}$} & \\
\hline & Malignant tumour & 3 & & & 1 \\
\hline Myocardium & & & Pericytes & & \\
\hline Cardiomyocytes & & & Circulatory changes & Intercellular oedema & 1 \\
\hline Circulatory changes & Haemorrhage & 1 & Regressive changes & Architectural and structural & \\
\hline & Intercellular oedema & 1 & & alterations & 1 \\
\hline Regressive changes & Architectural and structural & & & Plasma alterations & 1 \\
\hline & alterations & 1 & & Nuclear alterations & 2 \\
\hline & Plasma alterations & 1 & & Atrophy & 2 \\
\hline & Deposits & 1 & & Necrosis & 3 \\
\hline & Nuclear alterations & 2 & Progressive changes & Hypertrophy & 1 \\
\hline & Atrophy & 2 & & Hyperplasia & 2 \\
\hline & Necrosis & 3 & Tumour & Benign tumour & 2 \\
\hline Progressive changes & Hypertrophy & 1 & & Malignant tumour & 3 \\
\hline & Hyperplasia & 2 & Endocardium & & \\
\hline Inflammation & Exudate & 1 & Endothelial cells & & \\
\hline & Infiltration & 2 & Circulatory changes & Congestion & 1 \\
\hline Tumour & Benign tumour & 2 & & Intercellular oedema & 1 \\
\hline & Malignant tumour & 3 & Regressive changes & $\begin{array}{l}\text { Architectural and structural } \\
\text { alterations }\end{array}$ & 1 \\
\hline $\begin{array}{l}\text { Fibroelastic tissue } \\
\text { Circulatory changes }\end{array}$ & Haemorrhage & 1 & & Plasma alterations & 1 \\
\hline Reoressive changes & Deposits & 1 & & Deposits & 1 \\
\hline Regressive cnanges & Deposits & 1 & & Nuclear alterations & 2 \\
\hline Progressive changes & Hypertrophy & 1 & & Atrophy & 2 \\
\hline & Hyperplasia & 2 & & Necrosis & 3 \\
\hline Inflammation & Exudate & 1 & Progressive changes & Hypertrophy & 1 \\
\hline & Infiltration & 2 & & Hyperplasia & 2 \\
\hline Tumour & Benign tumour & 2 & Inflammation & Exudate & 1 \\
\hline & Malignant tumour & 3 & & Infiltration & 2 \\
\hline
\end{tabular}


Table 1 (continued)

\begin{tabular}{|c|c|c|c|c|c|}
\hline $\begin{array}{l}\text { Tissue and cell type } \\
\text { Reaction pattern }\end{array}$ & Alteration & I & $\begin{array}{l}\text { Tissue and cell type } \\
\text { Reaction pattern }\end{array}$ & Alteration & I \\
\hline \multirow[t]{2}{*}{ Tumour } & Benign tumour & 2 & \multirow[t]{2}{*}{ Regressive changes } & \multirow{2}{*}{$\begin{array}{l}\text { Architectural and structural } \\
\text { alterations }\end{array}$} & \\
\hline & Malignant tumour & 3 & & & 1 \\
\hline Valves & & & & Plasma alterations & 1 \\
\hline Fibroelastic tissue & & & & Deposits & 1 \\
\hline Circulatory changes & Haemorrhage & 1 & & Nuclear alterations & 2 \\
\hline \multirow[t]{8}{*}{ Regressive changes } & Deposits & 1 & & Atrophy & 2 \\
\hline & Intercellular oedema & 1 & & Necrosis & 3 \\
\hline & Architectural and structural & & \multirow[t]{2}{*}{ Progressive changes } & Hypertrophy & 1 \\
\hline & alterations & 1 & & Hyperplasia & 2 \\
\hline & Plasma alterations & 1 & \multirow[t]{2}{*}{ Inflammation } & Exudate & 1 \\
\hline & Nuclear alterations & 2 & & Infiltration & 2 \\
\hline & Atrophy & 2 & \multirow[t]{2}{*}{ Tumour } & Benign tumour & 2 \\
\hline & Necrosis & 3 & & Malignant tumour & 3 \\
\hline \multirow[t]{2}{*}{ Progressive changes } & Hypertrophy & 1 & \multirow{3}{*}{$\begin{array}{l}\text { Fibroelastic tissue } \\
\text { Circulatory changes }\end{array}$} & & \\
\hline & Hyperplasia & 2 & & Haemorrhage & 1 \\
\hline \multirow[t]{2}{*}{ Inflammation } & Exudate & 1 & & Intercellular oedema & 1 \\
\hline & Infiltration & 2 & Regressive changes & Deposits & 1 \\
\hline \multirow[t]{2}{*}{ Tumour } & Benign tumour & 2 & \multirow[t]{2}{*}{ Progressive changes } & Hypertrophy & 1 \\
\hline & Malignant tumour & 3 & & Hyperplasia & 2 \\
\hline \multirow{4}{*}{$\begin{array}{l}\text { Bulbus arteriosus } \\
\text { Cardiomyocytes } \\
\text { Circulatory changes }\end{array}$} & & & \multirow[t]{2}{*}{ Inflammation } & Exudate & 1 \\
\hline & & & & Infiltration & 2 \\
\hline & Haemorrhage & 1 & \multirow[t]{2}{*}{ Tumour } & Benign tumour & 2 \\
\hline & Intercellular oedema & 1 & & Malignant tumour & 3 \\
\hline
\end{tabular}

signed depending on the impact of the alteration on the heart functional condition. These importance factors ranged from 1 to 3 , where 1 is minimal impact, 2 is moderate pathological importance, and 3 is severe pathological importance (Table 1). The chosen values of the importance factors were based on the model for determination of tissue indices as described by Bernet et al. (1999). The classification of the pathological importance of an alteration is based on its reversibility. Pathological alterations that were reversible were classified with an importance factor of 1 , whereas those that were reversible in most cases were classified as 2 , and those that were irreversible were classified as 3 (Bernet et al. 1999, Haschek et al. 2010).

The score values were determined depending on the degree and extent of the alteration. Changes in the heart were scored from very mild (1) to severe (6), and the following classifications were applied: unchanged (0); mild occurrence (2); moderate occurrence (4); and severe occurrence (6). Intermediate values, namely (1), (3) and (5) were also considered (Bernet et al. 1999).

For each of the determined alterations, the score value was multiplied by the importance factor, resulting in an alteration index (Bernet et al. 1999). The tis- sue index was calculated as the sum of the alteration indices of the respective cell types of the functional tissue units (Eq. 1 below; Table 1). The following functional tissue units were evaluated: coronary blood vessels, coronary capillaries, intramyocardial capillaries, epicardium, endocardium, myocardium, valves and bulbus arteriosus (Fig. 1A). Afterwards, the heart index (Eq. 2) was calculated as the sum of the tissue indices.

$$
\begin{gathered}
\text { Functional unit index }= \\
\left.\sum \text { (score value } \times \text { importance factor }\right) \\
\text { Heart index }=\sum \text { (functional unit indices) }
\end{gathered}
$$

\section{Evaluation of the protocol}

To test the applicability, the scheme was applied on heart sections from the study of Steinbach et al. (2014) (Fig. 1). The alterations within the functional units in fish exposed to atenolol and control fish are listed below. In the respective groups, the tissue indices were calculated based on the heart scheme for each of the functional units. Based on the heart scheme, the heart indices for both groups were then calculated. 


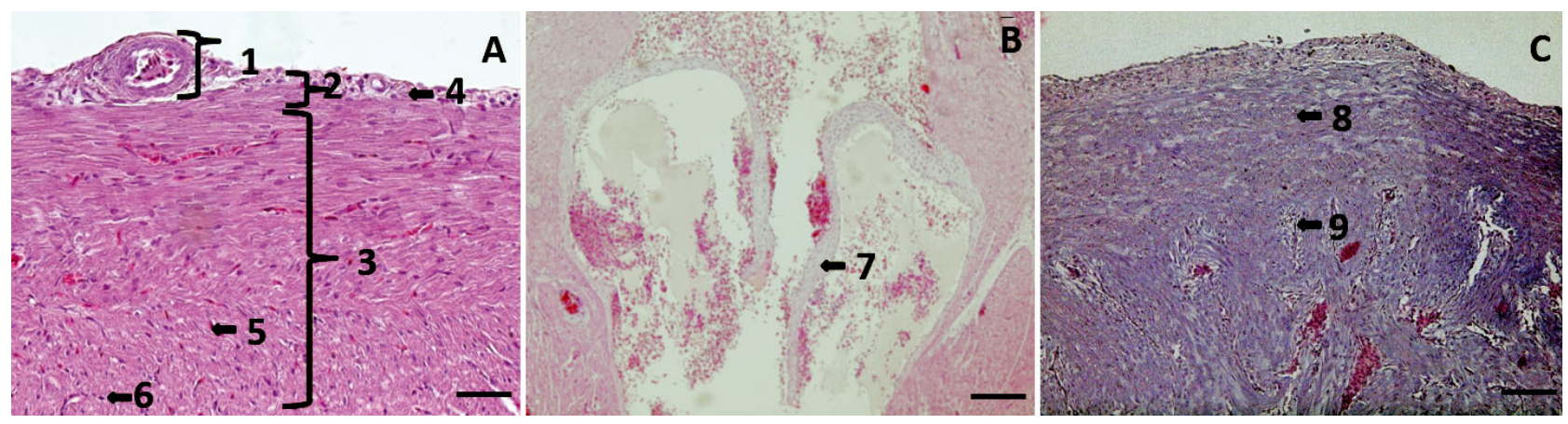

Fig. 1. Anatomic structure of the (A) heart ventricle, (B) valves and (C) bulbus arteriosus of rainbow trout Oncorhynchus mykiss. 1 = coronary blood vessel, myocardial capillary, $2=$ epicardium, $3=$ myocardium, $4=$ coronary capillary, $5=$ intramyocardial capillary, $6=$ endocardium, $7=$ fibroelastic tissue, $8=$ cardiomyocytes, $9=$ fibroelastic tissue. H\&E staining; scale bars $=(\mathrm{A}) 25 \mu \mathrm{m},(\mathrm{B}, \mathrm{C}) 50 \mu \mathrm{m}$

\section{Histopathological alterations in the rainbow trout heart}

Coronary and myocardial blood vessels. The tissue index of the coronary blood vessels was significantly increased in the exposed fish compared to the controls (K-S test, $\mathrm{p}<0.005$ ). The coronary blood vessels had a tissue index of 0 (median) (0 [lower quartile], 1 [upper quartile]) in the controls and $10(6.5,12)$ in exposed fish (Fig. S1A in the Supplement, available at www.int-res.com/articles/ suppl/d118p185_supp.pdf). Qualitatively, comparable lesions were found in both groups. The membranes of endothelial cells as well as the basement membrane displayed ruptures. In addition, in control and exposed fish, intercellular oedema was found as well as signs of an inflammatory reaction; this was defined as an infiltration with lymphocytes and macrophages (Fig. 2A). The connective tissue in both groups showed intercellular oedema and infiltration with the same inflammatory cells (Fig. 2A). The coronary and intramyocardial capillaries were not altered (Fig. S1A).

Epicardium. The tissue index of the epicardium was significantly increased in the exposed fish compared to the controls (K-S test, $\mathrm{p}<0.005)$. The tissue index for the epicardium was estimated in control and exposed fish as $2.6(2,4)$ and $7.5(5.5,10)$, respectively (Fig. S1B). The epicardium in exposed animals was haemorrhagic, and in both control and exposed fish, it was infiltrated by lymphocytes and macrophages (Fig. 2A). The pericardial connective tissue of exposed animals also showed signs of an inflammatory reaction and was found to be oedematous.
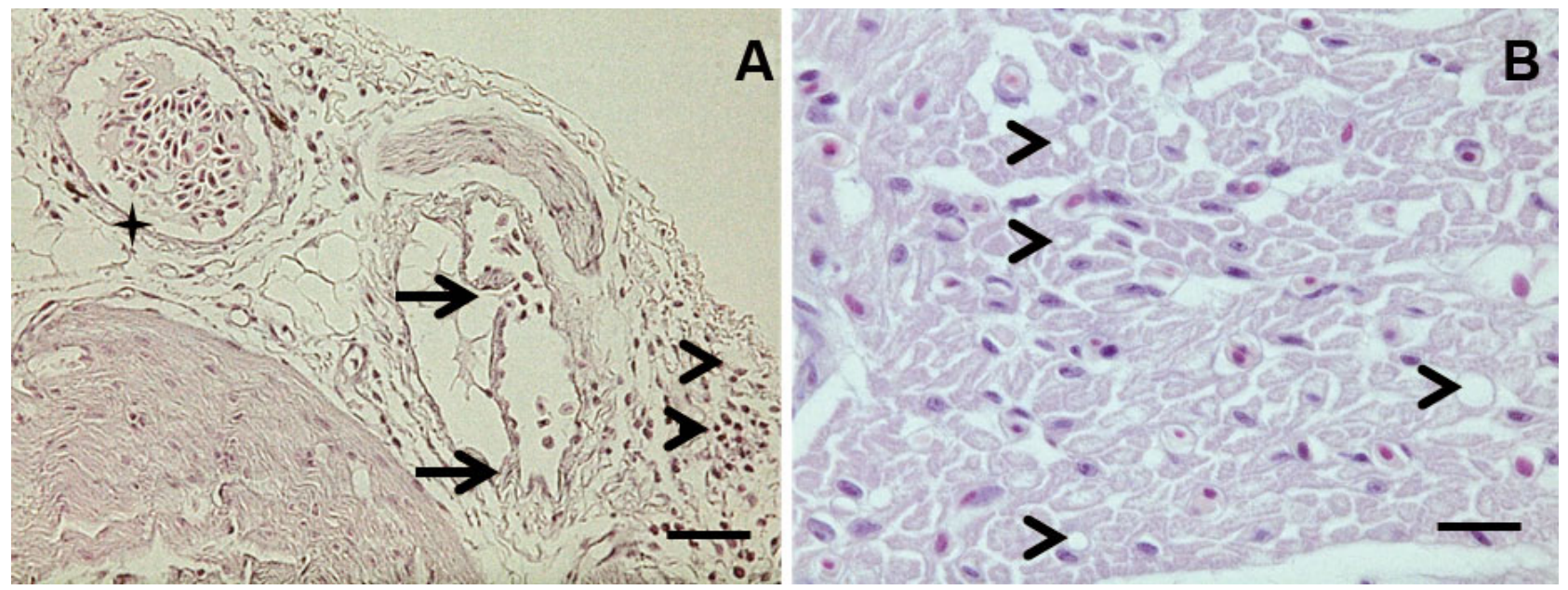

Fig. 2. Histopathological findings in the heart of rainbow trout Oncorhynchus mykiss exposed to $1000 \mu \mathrm{g} \mathrm{l}^{-1}$ atenolol. (A) Exposed fish showed epicardial infiltration with lymphocytes, plasma cells and macrophages (arrowheads) and degeneration of the coronary blood vessel (arrows), area with unaltered blood vessels and epicardium (star). (B) Exposed fish presented an intracellular vacuolization of the myocardium (oedematous) (arrowheads). H\&E staining; scale bars $=50 \mu \mathrm{m}$ 
Myocardium. The tissue index of the myocardium was significantly increased in the exposed fish compared to the controls (K-S test, $\mathrm{p}<0.05$ ). The tissue index for the myocardium was estimated in control and exposed fish at $0.5(0,1)$ and $2.6(1,4)$, respectively. The cardiomyocytes of exposed animals were oedematous (Fig. 2B) and presented signs of an inflammatory reaction (Fig. 2B, Fig. S1B). No alterations were found in the fibroelastic tissue.

Endocardium. The tissue index in the endocardium of fish exposed to atenolol did not differ significantly from the controls but showed some minor differences. The tissue index for the endocardium was estimated at $0(0,0)$ and $0(0,3)$ in control and exposed fish, respectively. The endothelial cells of 2 exposed animals were oedematous and presented signs of necrosis and an inflammatory reaction (Fig. S1B).

Valves. The tissue index in the valves of fish exposed to atenolol did not differ significantly from the control but showed some minor differences. The tissue index for the valves was estimated in control and exposed fish at $0.1(0,1)$ and $0.8(0,1)$, respectively (Fig. S1B). In both groups, the fibroelastic tissue was oedematous. The fibroelastic tissue of the exposed fish showed signs of hypertrophy.

Bulbus arteriosus. The tissue index in the bulbus arteriosus of fish exposed to atenolol did not differ significantly from the control. The bulbus arteriosus had a tissue index of $0.5(0,1)$ and $1.5(0.5,4.4)$ in control and exposed fish, respectively (Fig. S1B). In both groups, the cardiomyocytes showed signs of intracellular oedema and were infiltrated by macrophages. In the exposed fish, the fibroelastic tissue additionally displayed intercellular oedema.

\section{Heart index}

The histopathological alterations found in fish exposed to atenolol and control fish, as well as the calculations of the heart indices, assessed by both observers, are presented in Fig. 3. Fish exposed to atenolol had a significantly higher heart index when compared to the control group (K-S test, $\mathrm{p}<0.005$; Fig. 3). This was confirmed by both observers.

\section{Inter-observer agreement}

Within the majority of assessed parameters, there was high agreement between the observers. To test reliability, we computed Spearman's correlation be-

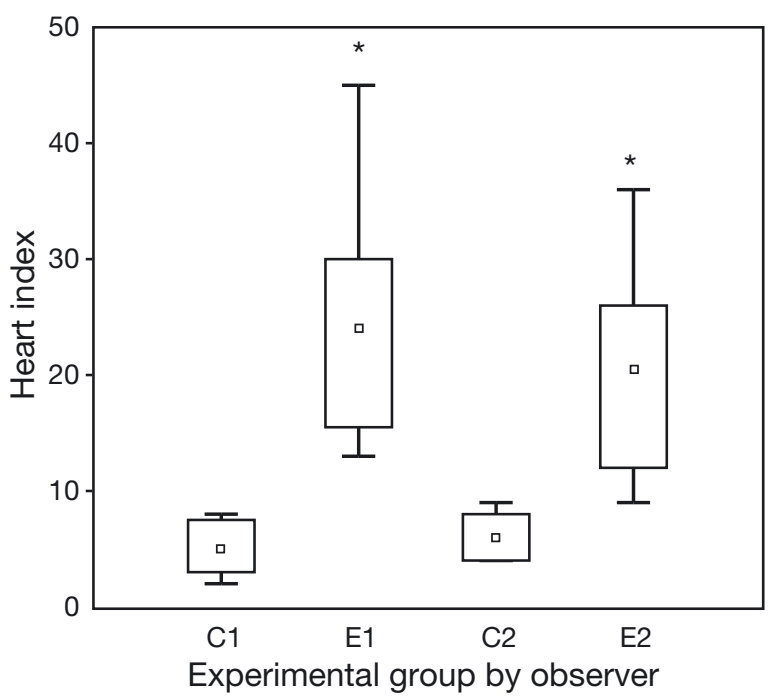

Fig. 3. Heart indices of rainbow trout Oncorhynchus mykiss from the control group (C) and the group exposed to $1000 \mu \mathrm{g} \mathrm{l^{-1 }}$ atenolol (E). Boxes show the first to third quartiles, and whiskers are minimum and maximum values. The evaluation was performed inter-observer blinded by 2 observers, 1 and 2. Asterisks indicate significant differences in atenolol-exposed fish compared to the controls (K-S test, ${ }^{*} \mathrm{p}<0.05 ; \mathrm{n}=8$ )

tween results given by observer 1 and the observer 2 . The value of Spearman's correlation coefficient was 0.92 , which was significant $(\mathrm{p}<0.001)$. The individual heart indices obtained by both observers are given in Fig. S2 in the Supplement.

\section{Heart protocol applied to fish belonging to other orders}

The scheme was tested on sturgeon, percid and cyprinid fishes using slides from a previous diagnostic study; these were re-evaluated according to the presented protocol. All functional tissue units in the hearts of those fish species could be assessed and a heart index could be calculated. This heart index was in agreement with the qualitative assessment done by the CFWH. Therefore, our protocol was found to be applicable to species other than rainbow trout. Differences from the rainbow trout model were increased blood content in coronary blood vessels in small fish species, such as zebrafish (Fig. 4A) or European perch (Fig. 4B), high amounts of epicardial lipid tissue in koi carp (Fig. 4C) and subepicardial haematopoietic tissue in Russian sturgeon (Fig. 4D). These species-specific features were not included in the heart protocol to keep it more widely applicable. 


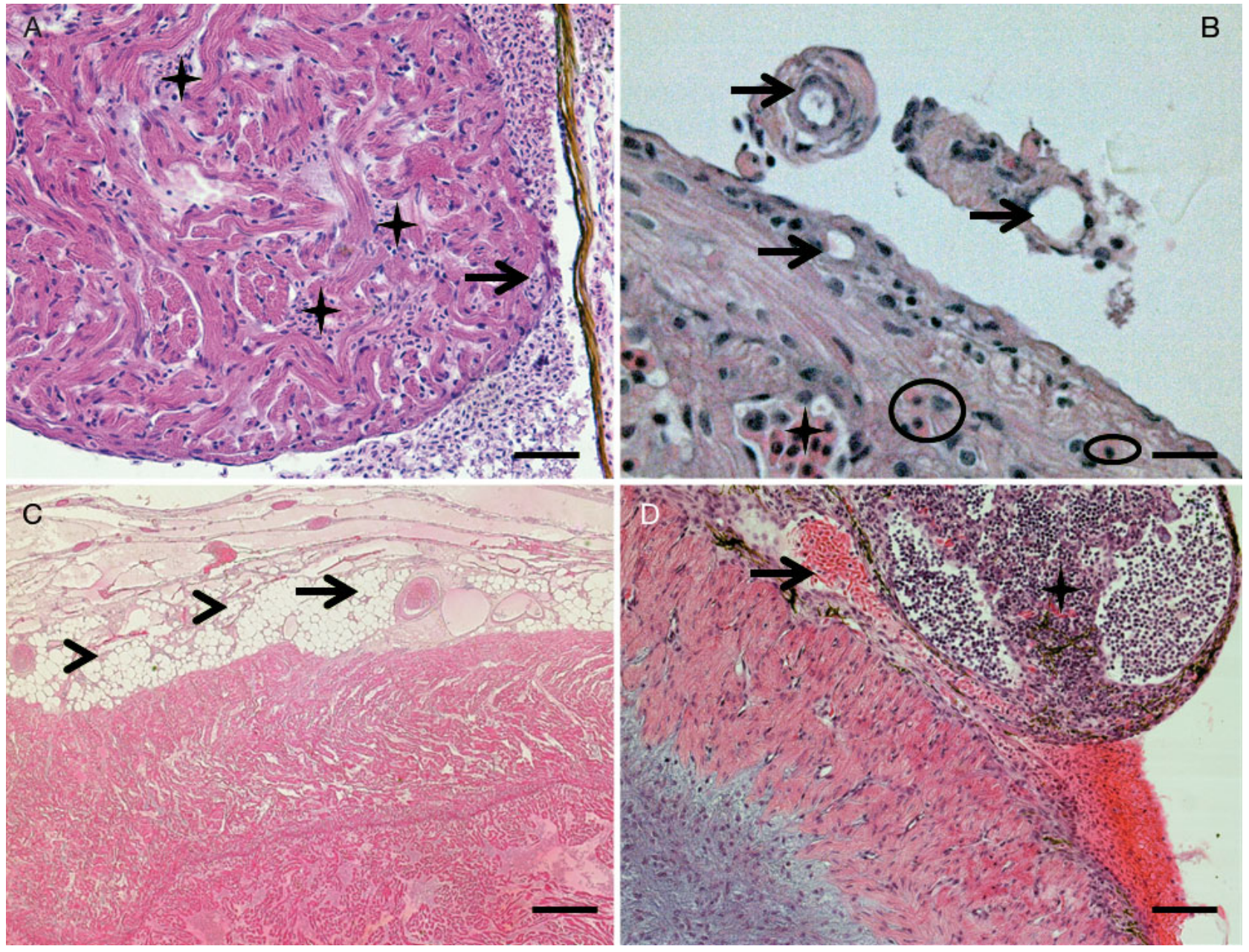

Fig. 4. Anatomic structure of the hearts of 2 representative cyprinids, a percid and a sturgeon. (A) In juvenile zebrafish Danio rerio, the ventricle is filled with blood (stars), the coronary blood vessel is indicated by the arrow. (B) In European perch Perca fluviatilis, the ventricle is partly filled with remaining blood (star), with well pronounced coronary blood vessels (arrows) and the intramyocardial capillaries in the myocardium (encircled). (C) In koi carp Cyprinus carpio, the lipid tissue in the epicardium (arrowheads) is partly embedding the coronary blood vessel (arrow). (D) The heart of Russian sturgeon Acipenser gueldenstaedtii is characterised by the subepicardial haematopoietic tissue (star) close to the coronary blood vessels (arrow). H\&E staining; scale bars $=(A, D) 50 \mu m,(B, C) 100 \mu \mathrm{m}$

\section{DISCUSSION}

Histopathological alterations in the heart of fish can be caused by various compounds such as heavy metals, pharmaceuticals and pesticides (Mohamed 2008, Magar \& Dube 2013, Steinbach et al. 2014). Because there has been no standardized evaluation method, these alterations are typically presented in a qualitative way without the possibility of statistical evaluation (Mohamed 2008, Magar \& Dube 2013, Steinbach et al. 2014).

In the present work, we developed a protocol for a quantitative standardized assessment of histopathological changes in the fish heart, including coronary blood vessels, coronary and intramyocardial capillaries, epicardium, endocardium and myocardium of the ventricle and atrium, bulbus arteriosus and valves, employing a heart index. Histopathological alterations in the heart of atenolol-exposed rainbow trout were re-assessed and quantified. Heart indices calculated in the present study for atenolol-exposed and control fish were significantly different, which was well in line with the results of the previous qualitative assessment (Steinbach et al. 2014). Furthermore, the functional unit indices were elevated exactly in those tissues which had been found to be altered in the previous study. Steinbach et al. (2014) demonstrated that atenolol had an effect on the vascular 
system, as evidenced by the observed changes in the epicardium and myocardium and further alterations in the vessels in exposed fish. In detail, Steinbach et al. (2014) reported the following alterations in the heart: inflammation in the epicardium, oedematous pericardial fibrous tissue, infiltration in the subendocardial space, myocardial oedema, thickened and oedematous vessel walls and disruption of endothelial cells.

Thus, our protocol was applicable for assessing histopathological alterations in the heart of rainbow trout. In the present study, the calculation of the heart index was based on the calculation of the indices of each functional unit. In addition, these indices can be used as indicators of damage at the level of the functional unit and allow an easy localisation of the alterations within the tissue.

In addition to rainbow trout, which is used in toxicological research as a model species (OECD 2012), our protocol was successfully applied to zebrafish, another model species (OECD 2012), as well as several other fish species belonging to different systematic families. However, special anatomic features, such as the haematopoietic tissue in the epicardium of sturgeons, were not included in the protocol, as we wanted to avoid generating a species-specific index that would not be comparable to those of other species. Species-specific patterns should be reported separately and not included in the heart index.

Moreover, alterations in the lipid content of the epicardium were not included in the protocol, because it is highly variable among species and also among individuals within the same species. Thus it should also be reported separately. However, in farmed salmon, epicardial fat is generally considered a negative trait (Bruno et al. 2013). In case of tumours, we recommend that they be classified according to the World Health Organization classification developed for mammals (Slayter et al. 1994) and to determine the cells of origin. For example, the haemangioma is found as a typical neoplasm of the vascular system and can be induced by aniline compounds, vinyl toluene and 1,3-butadiene in mammals (Haschek et al. 2010).

Unlike the heart in mammals, the heart of adult fish possesses a high capability of regeneration (Itou et al. 2014). This regeneration is similar to the skeletal muscle regeneration pattern in mammals (McGavin et al. 2001) and is indicated by an increased number of nuclei per myocyte and a hyperplasia of cardiomyocytes (Takashima \& Hibiya 1995). Therefore, a qualitative description of the changes is still necessary to distinguish e.g. between degenerative or re- generative changes possibly showing similar indices. To overcome this dilemma, the indices for different pathology patterns, such as regenerative and progressive changes, can be reported independently, allowing a further classification of the determined processes.

As gross pathological alterations of the heart, i.e. cardiac anomalies, are important indicators (Poppe \& Ferguson 2006, Roberts 2012), we recommend reporting these alterations in addition to the heart index.

The heart is sensitive to a variety of infectious and non-infectious diseases with different aetiologies, e.g. viruses, bacteria, fungi or parasites, as well as nutritional deficits. In aquaculture, heart diseases are of economic importance (Bruno et al. 2013). The presented protocol, if adapted, could also be applied in the description of various diseases. However, for diagnostic purposes, disease-specific patterns are more meaningful than any tissue index. The implementation of the heart index might be an oversimplification of the complexity of the disease in fish, and its meaningfulness or significance in diagnostics may be doubtful. Because pathogen-induced alterations cannot always be easily distinguished from those caused by chemical factors, the whole fish should always be examined to rule out pathogen-induced changes.

As unified diagnostic criteria can help to increase the understanding of the toxicological/pathological effects on the heart, further studies are needed to demonstrate the connection and importance of the assessed parameters and the effect on the heart condition. We suggest that the applied scoring system be connected to numeric data. This approach should be based on clear definitions of pathological alterations, as given in the presented protocol for alterations in the heart.

\section{CONCLUSION}

Our protocol for the quantitative assessment of histopathological alterations in the heart ventricle, atrium, bulbus arteriosus, valves and coronary blood vessels was found to be applicable to several fish species. In addition, this protocol enables a quantifiable evaluation of the alterations within the functional units of the heart (coronary blood vessels, coronary and intramyocardial capillaries, epicardium, endocardium and myocardium of the ventricle and atrium, bulbus arteriosus and valves). Furthermore, to enhance the power of this model, we recommend reporting gross morphological changes, alterations in 
lipid content, signs of regeneration, tumour classification and species-specific patterns, such as alterations in haematopoietic tissue, separately. However, the application of our protocol in diagnostics of diseases has not yet been evaluated. Given the potentially complex effects generated by pathogens, our protocol might be an oversimplification and may not reflect the full extent of alterations; in particular, it might not enable us to obtain information on the aetiology. Therefore, the protocol cannot be recommended for diagnostic purposes at present. For the future, our protocol offers the possibility of a comparison between different toxicological studies and allows a better quantification of dose dependencies in the assessment of toxic effects.

Acknowledgements. This study was funded by the Ministry of Education, Youth and Sports of the Czech Republic - projects 'CENAKVA' (No. CZ.1.05/2.1.00/01.0024), 'CENAKVA II' (No. LO1205 under the NPU I program), USB projects (GAJU No. 087/2013/Z) and a project of the Czech Science Foundation (No. 503/11/1130).

\section{LITERATURE CITED}

Bernet D, Schmidt H, Meier W, Burkhardt-Holm P, Wahli T (1999) Histopathology in fish: proposal for a protocol to assess aquatic pollution. J Fish Dis 22:25-34

Bruno DN, Patricia A, Poppe TT (2013) A colour atlas of salmonid diseases, $2^{\text {nd }}$ edn. Springer Science \& Business Media, Dordrecht

Feist SW, Segner H (2013) Short course on toxicologic pathology in fish. Bull Eur Assoc Fish Pathol 33:100-104

Genten F, Terwinghe E, Danguy A (2009) Atlas of fish histology. Science Publishers, Enfield, NH

Haschek WM, Rousseaux CG, Wallig MA (2010) Handbook of toxicologic pathology. Academic Press, San Diego, CA

$>$ Itou J, Akiyama R, Pehoski S, Yu XD, Kawakami H, Kawakami Y (2014) Regenerative responses after mild heart injuries for cardiomyocyte proliferation in zebrafish. Dev Dyn 243:1477-1486

Magar RS, Dube KV (2013) Effect of sub lethal concentration of malathion on metabolic profiles and histological stud-

Editorial responsibility: Thomas Braunbeck, Heidelberg, Germany ies in heart tissue of Channa punctatus. IOSR J Environ Sci Toxicol Food Technol 2:8-12

Marchand MJ, van Dyk JC, Barnhoorn IEJ, Wagenaar GM (2012) Histopathological changes in two potential indicator fish species from a hyper-eutrophic freshwater ecosystem in South Africa: a baseline study. Afr J Aquat Sci 37:39-48

McGavin MD, Carlton W, Zachary JF, Thomson RG (2001) Thomson's special veterinary pathology. Mosby, St. Louis, MO

Mohamed FAS (2008) Bioaccumulation of selected metals and histopathological alterations in tissues of Oreochromis niloticus and Lates niloticus from Lake Nasser, Egypt. Global Vet 2:205-218

OECD (Organization for Economic Cooperation and Development) (2012) Guidelines for the testing of chemicals. Section 3: degradation and accumulation. TG-No. 305: bioaccumulation in fish: aqueous and dietary exposure. OECD, Paris

Poppe TT, Ferguson HW (2006) Cardiovascular system. In: Ferguson HW (ed) Systemic pathology of fish, $2^{\text {nd }}$ edn. Scotian Press, London, p 140-167

Raskovic B, Jaric I, Koko V, Spasic M, Dulic Z, Markovic Z, Poleksic V (2013) Histopathological indicators: a useful fish health monitoring tool in common carp (Cyprinus carpio Linnaeus, 1758) culture. Cent Eur J Biol 8:975-985

Roberts RJ (2012) Fish pathology. Wiley-Blackwell, Hoboken, NJ

Schmidt H, Bernet D, Wahli T, Meier W, Burkhardt-Holm P (1999) Active biomonitoring with brown trout and rainbow trout in diluted sewage plant effluents. J Fish Biol 54:585-596

Slayter MV, Hendrick MJ, Goldschmidt MH, Kennedy PC, Koestner A, Dungworth DL (1994) International histological classification of tumors of domestic animals, $2^{\text {nd }}$ series. Armed Forces Institute of Pathology in cooperation with the American Registry of Pathology and the World Health Organization Collaborating Center for Comparative Oncology, Washington, DC

Steinbach C, Burkina V, Fedorova G, Grabicova K and others (2014) The sub-lethal effects and tissue concentration of the human pharmaceutical atenolol in rainbow trout (Oncorhynchus mykiss). Sci Total Environ 497-498: 209-218

Takashima F, Hibiya T (1995) An atlas of fish histology: normal and pathological features. Kodansha, Tokyo (distributor: Gustav Fischer, Stuttgart)

Submitted: March 5, 2015; Accepted: January 28, 2016 Proofs received from author(s): March 11, 2016 